\title{
Effects of Percutaneous Sacroplasty on Pain and Mobility in Sacral Insufficiency Fracture
}

\author{
Kyung-Chul Choi, M.D., Ph.D., ${ }^{1}$ Seung-Ho Shin, M.D., ${ }^{1}$ Dong Chan Lee, M.D., ${ }^{1}$ Hyeong-Ki Shim, M.D., \\ Choon-Keun Park, M.D., Ph.D. ${ }^{2}$ \\ Department of Neurosurgery, the Leon Wiltse Memorial Hospital, Anyang, Korea \\ Department of Neurosurgery, ${ }^{2}$ the Leon Wiltse Memorial Hospital, Suwon, Korea
}

Objective : Sacral insufficiency fracture (SIF) contributes to severe low back pain. Prolonged immobilization resulting from SIF can cause significant complications in the elderly. Sacroplasty, a treatment similar to vertebroplasty, has recently been introduced for providing pain relief in SIF. The purpose of this study is to investigate the clinical short-term effects of percutaneous sacroplasty on pain and mobility in SIF.

Methods : This study is conducted prospectively with data collection. Sixteen patients ( 3 men and 13 women) with a mean age of 77.5 years (58 to 91) underwent sacroplasty. Patients reported visual analogue scale (VAS; $0-10$ ) and Oswestry disability index (ODI; $0-100 \%)$ scores. VAS and ODI scores were collected preoperatively and again at one day, one month, and three months postoperatively. Questionnaires measuring six activities of daily living (ADLs) including ambulating, performing housework, dressing, bathing, transferring from chair, and transferring from bed were collected. Ability to perform ADLs were reported preoperatively and again at three months postoperatively.

Results : The mean preoperative VAS score (mean \pm SD) of $7.5 \pm 0.8$ was significantly reduced to $4.1 \pm 1.6,3.3 \pm 1.0$, and $3.2 \pm 1.2$ postoperatively at one day, one month, and three months, respectively $(p<0.01)$. The mean ODI score $(\%)$ also significantly improved from $59 \pm 14$ preoperatively to $15.5 \pm 8.2$ postoperatively at one month and $14.8 \pm 8.8$ at three months $(p<0.01)$. All ADL scores significantly improved at three months postoperatively $(p<0.01)$.

Conclusion : Percutaneous sacroplasty alleviates pain quickly and improves mobility and quality of life in patients treated for SIF.

Key Words : Percutaneous sacroplasty · Vertebroplasty · Sacral insufficiency fracture · Activities of daily living · Mobility · Quality of life.

\section{INTRODUCTION}

Sacral insufficiency fracture (SIF) was first recognized by Lourie $^{24)}$. SIF typically presents lower back, pelvis, buttock, or groin pain. It is often misdiagnosed or underdiagnosed upon initial examination ${ }^{8,22}$. SIF contributes to acute, severe low back pain and can occur as a complication of osteoporosis, metabolic disorders, metastatic cancer, or trauma. Prolonged immobilization and hospitalization can cause significant complications in the elderly ${ }^{2}$. Pelvic insufficiency

• Received: May 24, 2016 • Revised: August 22, 2016 •Accepted: September 27, 2016

-Address for reprints : Choon-Keun Park, M.D., Ph.D.

Department of Neurosurgery, the Leon Wiltse Memorial Hospital, 437 Gyeongsu-daero, Paldal-gu, Suwon 16480, Korea

Tel : +82-31-240-6280, Fax : +82-31-240-6281, E-mail : allspine@gmail.com

This is an Open Access article distributed under the terms of the Creative Commons Attribution Non-Commercial License (http://creativecommons.org/licenses/by-nc/4.0) which permits unrestricted non-commercial use, distribution, and reproduction in any medium, provided the original work is properly cited. 
fractures, including SIF, have a one-year mortality rate of $15 \%$, and $50 \%$ of pelvic insufficiency fracture patients do not recover to their pre-fracture state ${ }^{30)}$.

Percutaneous sacroplasty was introduced in 2002 as a minimally invasive treatment for SIF, similar to vertebroplasty ${ }^{14,17)}$. It is indicated as a therapeutic option for pain relief and improved mobility ${ }^{15,19)}$. Most research is limited to technical reports and case series ${ }^{6,9,29)}$. The purpose of this analysis is to investigate the clinical short-term effects of sacroplasty in reducing pain and improving mobility in elderly patients suffering from SIFs.

\section{MATERIALS AND METHODS}

Approval was obtained from our institutional review board for this study. The study was conducted by prospective data collection. All patients with osteoporotic SIF who underwent sacroplasty between December 2013 and September 2015 were included in this study. All patients underwent preoperative magnetic resonance imaging (MRI), computed tomography (CT), and radiography, and postoperative MRI or CT. Patients presenting with pathologic fractures were excluded from this study.

Patients reported their pain levels and ability to perform activities of daily living (ADLs) pre- and post-operatively. Patients reported pain scores on a scale from 1 (best) to 10 (worst) utilizing a visual analogue scale (VAS). Functional state was measured utilizing the Oswestry disability index

(ODI). The ODI is comprised of ten items, each of which contain six possible responses. Each item is scored from 0 to 5 points, and the sum of the scores is presented as a percentage $(0-100 \%)$. ADL questionnaires measuring mobility (ambulating, performing housework, dressing, bathing, transferring from chair, and transferring from bed) were collected. Each ADL was measured on a five-point scale (Table 1). VAS scores were collected preoperatively, and again at one day, one month, and three months postoperatively. ODI scores were collected preoperatively and again at one month and three months postoperatively. ADLs were measured preoperatively and again at three months postoperatively.

\section{Technique}

The distance between the target point and anterior sacral cortex was measured on preoperative CT scans. Three fluoroscopic images were obtained- anteroposterior (AP), anterior oblique, and lateral images. The entry point of needle in-

Table 1. Measurements of performing activities of daily livings on a 5-point scale

\begin{tabular}{lll}
\hline Ambulating & $\begin{array}{c}\text { Performing housework, } \\
\text { dressing, bathing, } \\
\text { transferring from chair, } \\
\text { transferring from bed }\end{array}$ \\
\hline 1 & Normal & Able to perform without pain \\
\hline 2 & Normal, with pain & Able to perform with mild pain \\
\hline 3 & Limited, with pain & Able to perform with moderate pain \\
4 & Wheelchair & Able to perform with severe pain \\
\hline 5 & Bedridden & Unable to perform because of pain \\
\hline
\end{tabular}
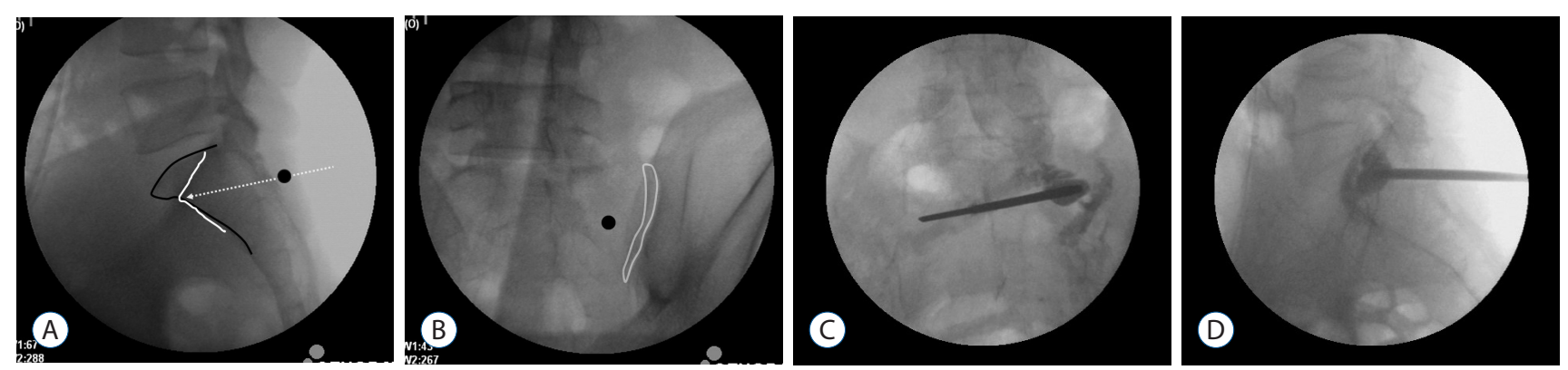

Fig. 1. Intraoperative radiography (A) showing the sacral body margin (black line) and ala margin (white line). The entry point is the infero-lateral margin of the S1 pedicle (black circle) and the needle is inserted parallel to the S1 upper endplate (white dotted line). Contralateral oblique radiography (B) showing ipsilateral SI joint space (white line). Antero-posterior (C) and lateral (D) radiographies showing polymethylmethacrylate cement in the sacral ala with no extravasation. SI : sacroiliac. 

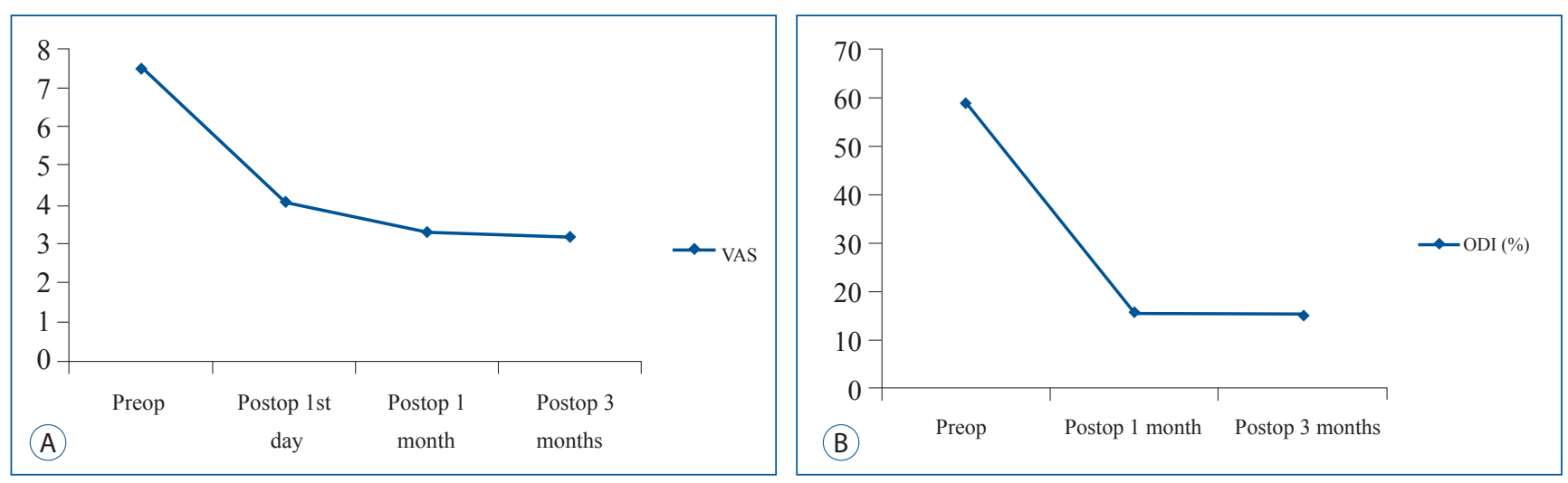

Fig. 2. Changes of VAS scores (A) and ODI scores (B) after percutaneous sacroplasty. VAS : visual analogue scale, ODI : Oswestry disability index.

sertion was the infero-lateral margin of S1 pedicle on AP image using a cephalo-caudal tilt parallel to L5-S1 disc space (Fig. 1A). On the contralateral oblique view, the ipsilateral sacroiliac (SI) joint was visible (Fig. 1B). The cannula was inserted approximately $2 \mathrm{~cm}$ with lateral 30-40 degree trajectory parallel to the SI joint on oblique view (Fig. 1C). On lateral view, the cannula was further advanced parallel to the S1 upper endplate while considering the depth of the sacral ala. When the needle tip was located on the target point, the cement was injected slowly while monitoring leakage in extraosseous area (Fig. 1D). In bilateral sacral fractures, the procedure was performed on the contralateral side via the same method.

\section{Statistical analysis}

The Wilcoxon signed-rank test was used to assess differences in the preoperative and postoperative clinical data. Statistical significance was defined as $p<0.05$.

\section{RESULTS}

Sixteen SIF patients (3 men and 13 women) with a mean age of 77.5 years (58 to 91 years) underwent sacroplasty between December 2013 and September 2015. Eleven SIFs were associated with antecedent trauma, and five developed without trauma (Table 2). SIF presented commonly with low back pain, and buttock and groin pain. Five patients suffered from radicular pain at L5 dermatome and three SIFs were con-

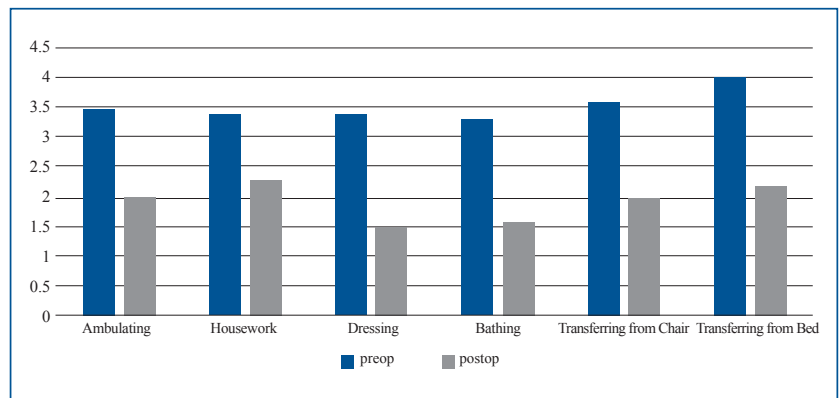

Fig. 3. ADLs including six items improved after sacroplasty, 3 months later. ADLs : activities of daily living.

comitant with lumbar compression fracture. Seven patients presented old thoracolumbar vertebral compression fractures. Only two patients took anti-osteoporotic medications. The preoperative mean symptom duration was 31.7 days (1120 days). Considering radiologic findings and symptomatic lesion, eight SIFs were treated with bilateral sacroplasty and seven were treated unilaterally. The mean preoperative VAS score (mean \pm standard deviation) was $7.5 \pm 0.8$. This was significantly reduced postoperatively to $4.1 \pm 1.6,3.3 \pm 1.0$, and 3.2 \pm 1.2 at one day, one month, and three months, respectively $(p<0.01 ;$ Fig. 2A). The mean ODI score (\%) also significantly improved from $59 \pm 14$ preoperatively to $15.5 \pm 8.2$ at one month and $14.8 \pm 8.8$ at three months postoperatively $(p<0.01$; Fig. 2B). Three months after sacroplasty, all ADL scores significantly improved ( $p<0.01$, Fig. 3 ). There were no complications associated with sacroplasty. Two cases developed cement anterior leakage through a crack in the fracture; however, the leakage did not cause problems. One patient required opioid analgesics for three months postoperatively. All 
Percutaneous Sacroplasty for SIF | Choi KC, et al.

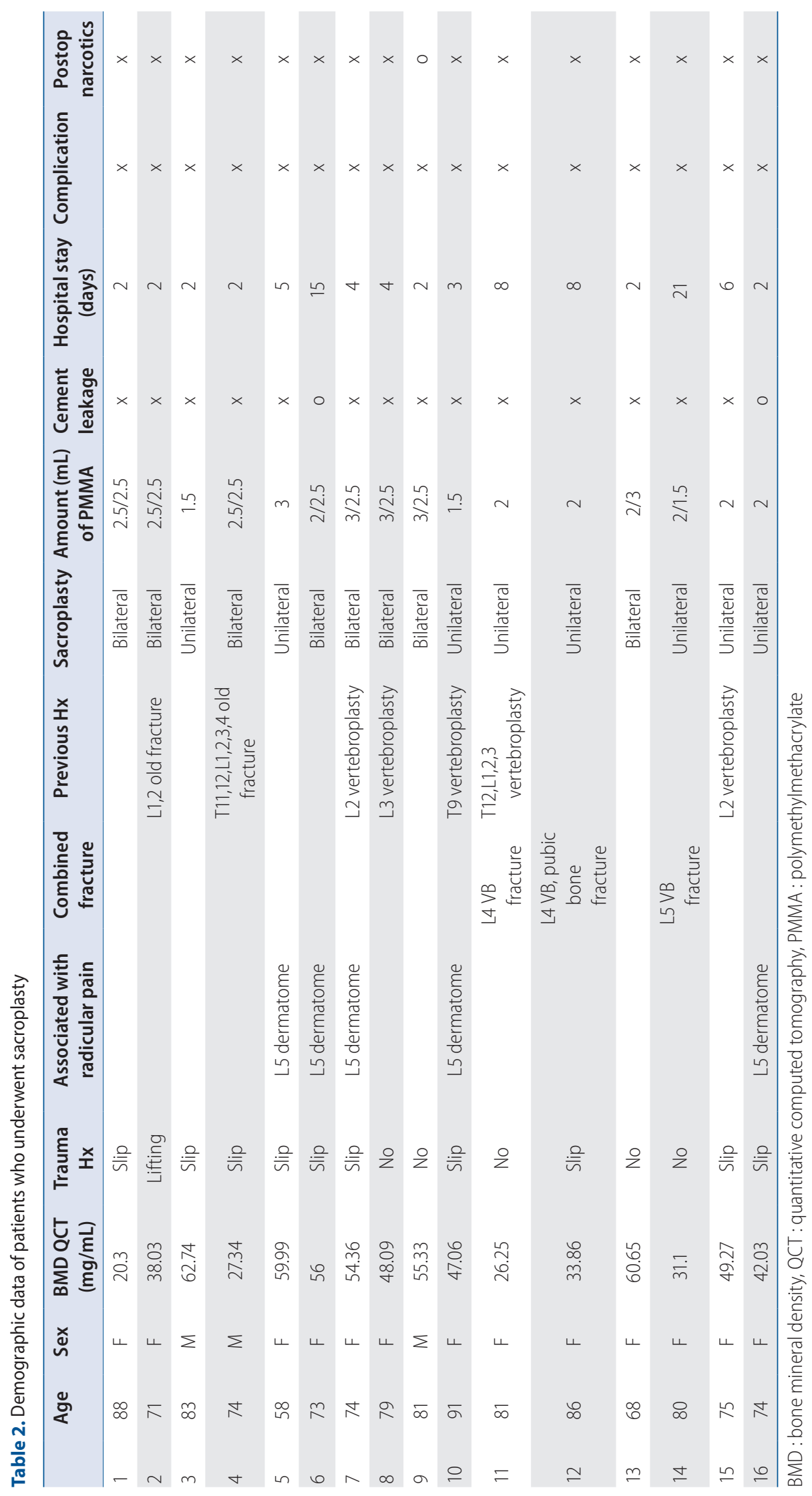


five patients presenting with preoperative radicular pain reported reduced pain following sacroplasty and nerve root block.

\section{DISCUSSION}

SIF is a stress fracture that occurs when normal stress is applied to decreased bone mass and quality. Osteoporosis, rheumatoid arthritis, long-standing steroid exposure, and pelvic irradiation are associated with SIF. SIF is often underdiagnosed or overlooked, especially when concomitant thoracolumbar fracture is present ${ }^{8,20,22)}$. SIF is difficult to diagnose, although plain radiography will expose cortical disruption or fracture line. Coronal and axial CT scan images help to visualize fracture lines. MR image and bone scintigraphy with technetium Tc99 m-labeled MDP are the most sensitive examinations ${ }^{7,27)}$. As found in our study, coronal short tau inversion recovery (STIR) MR image demonstrates a high intensity lesion in the early detection of bone marrow edema in SIF (Fig. 4) ${ }^{18)}$. Bone scintigraphy shows H-shaped uptake and has 96\% sensitivity for SIF with 92\% positive predictive value $^{16)}$.
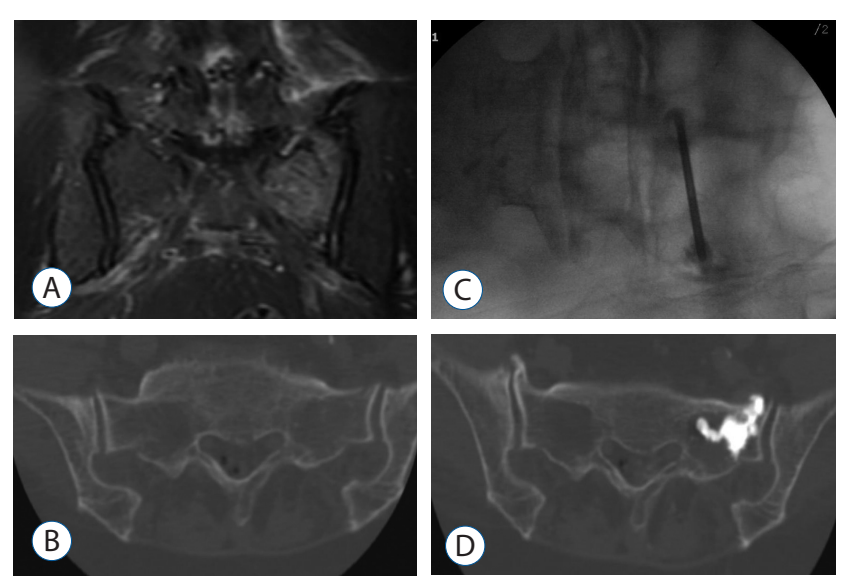

Fig. 4. A 74-years old woman presented with severe left buttock and leg radiating pain as the $L 5$ dermatome after slippage. A : Coronal STIR MR image showing bone marrow edema in the left sacrum. B : A CT scan showing cortical disruption of the left sacral ala. $C$ : Intraoperative radiography showing PMMA injection in the left sacral ala. $D:$ After the sacroplasty, the pain improved and CT scan showed PMMA in the sacral ala with minimal extraosseous minimal leakage. STIR : short tau inversion recovery, $\mathrm{MR}$ : magnetic resonance, $\mathrm{CT}$ : computed tomography, PMMA : polymethylmethacrylate.
In general, bed rest and pain management are regarded as standard treatments of SIF. Under these prescribed treatments, SIF may require up to 12 months to heal ${ }^{23)}$. However, prolonged immobilization in old age gives rise to cardiovascular complications, pressure ulceration, bone loss, and muscle wasting. Many patients do not recover to their previous functional state s,28,30,32) $^{2}$.

Percutaneous sacroplasty is indicated as a minimally invasive treatment for SIF (as is vertebroplasty for osteoporotic thoracolumbar fracture) and provides significant pain reduction and early and improved mobility. Sacroplasty can be performed under fluoroscopy or CT. Although CT guidance provides precise targeting and accurate needle placement by visualizing the bony complex, it cannot reflect real-time imaging nor absolutely prevent extravasation during the procedure.

The two techniques of sacroplasty are indicated depending on needle placement. Our study employed the short axis technique through the posterior approach. This technique is performed utilizing the S1 pedicle lateral margin or the S1 foramen bony margin with lateral divergence under fluoroscopy (Fig. 4). The ideal target zone is defined as the intersec-

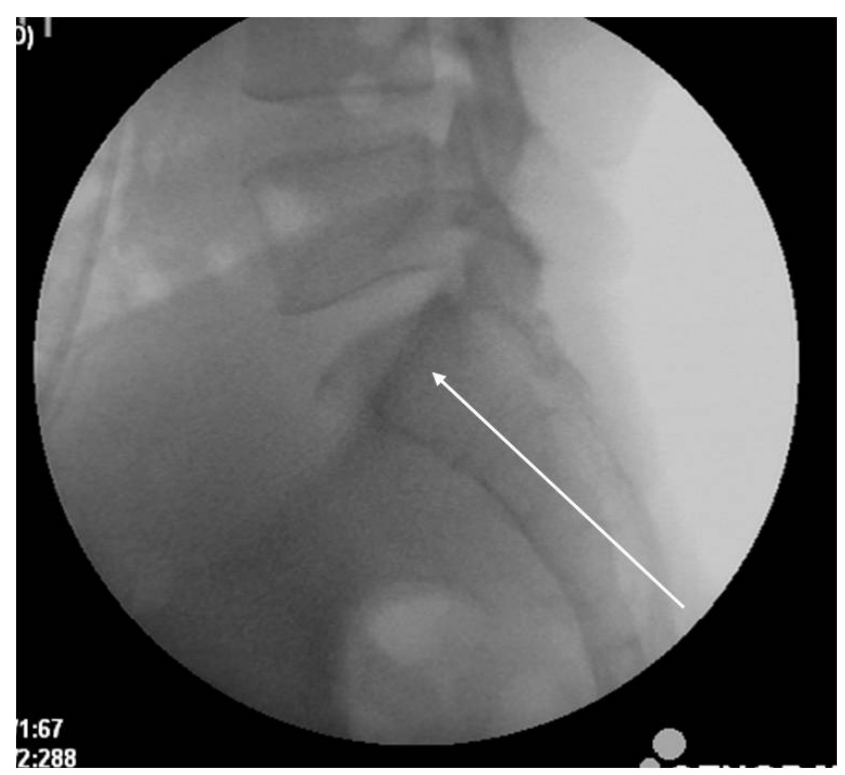

Fig. 5. Long axis injection technique. The entry point is between the inferior margin of the sacroiliac joint and the lateral margin of the S3 or S4 dorsal foramen. The needle trajectory (white line) advances to the mid-portion of the $\mathrm{S} 1$ body. 
tion of lines from the corners of $\mathrm{S1}^{21)}$. Combining a CT and conventional radiography provides precise needle placement and continued assessment of cement injection. A second approach, the long axis technique, disperses bone cement upon zone I of the sacral fracture laterally to the sacral neural foramen in a caudal-cephalad direction (Fig. 5). The entry point is the midpoint between the inferior margin of the SI joint and the lateral margin of the S3 or S4 neural foramen. The needle projects along the fractures of the sacral ala to decrease the risk of cement extravasation by inadvertently breaching the anterior cortex ${ }^{12,29)}$.

Sacroplasty provides significant pain reduction, and early and improved mobility. Opioid usage decreases in relation to pain reduction. Most studies reveal short-term analgesic effects ${ }^{19)}$. Frey et al. ${ }^{15)}$ reported $80 \%$ pain reduction at two weeks postoperatively and $90 \%$ pain reduction at 12 months after sacroplasty for SIF. A majority of symptoms including back, buttock, groin, and inguinal pain improved, as well as radicular pain caused by irritation of L5 exiting nerve root due to sacral ala fracture. CT-guided sacroplasty reports a $76 \%$ decrease in pain and a $60 \%$ decrease in opioid usage ${ }^{13)}$. Balloon-assisted sacroplasty may prevent polymethylmethacrylate (PMMA) migration, as kyphoplasty does for vertebral compression fracture ${ }^{11}$. In metastasis, multiple myeloma, and pelvic radiation necrosis as well, sacroplasty can provide pain relief ${ }^{4,10,25)}$.

Biomechanical effects of sacroplasty include a $40-60 \%$ reduction in strains locally around PMMA ${ }^{1)}$. On finite element analysis, sacroplasty decreased maximal stress at the point of sacral fracture by $83 \%$ and fracture gap micromotion by $48 \%{ }^{31)}$. The strength and stiffness bore no significant difference, regardless of the volume or location of PMMA ${ }^{26)}$. In our study, the mean amount of PMMA was $2.3 \mathrm{~mL}$ in each site.

PMMA leakage caused by breach of cortical bone due to PMMA needle or crack of the fracture site is a major concern. It is difficult to distinguish from ala bony shadow on lateral radiography imaging. Preoperative measurement of the distance between the target and anterior cortex is important. Leakages noted by various authors report 27\% PMMA leakage into the fracture gap, $6 \%$ into veins, $3 \%$ into the neu- ral foramen, and $2 \%$ into the disc space ${ }^{5}$. In one patient, it was reported that PMMA leakage lead to radicular pain, which was caused by the affected L5 nerve root. S1 radiculopathy due to extravasation into the $\mathrm{S} 1$ neural foramen has been reported ${ }^{3}$. Injection of contrast media helps recognize the location of the needle tip within the bone marrow so that the surgeon may avoid the neural foramen and SI joint. According to the literature, most of the small amount PMMA leakages were clinically insignificant.

This study employed a small sample size. The effectiveness of sacroplasty for SIF may be measured more clearly employing a control group that has first undergone conservative treatments.

\section{CONCLUSION}

Percutaneous sacroplasty alleviates pain quickly and improves mobility in patients suffering from SIF, thus improving the quality of life for those patients.

\section{References}

1. Anderson DE, Cotton JR : Mechanical analysis of percutaneous sacroplasty using CT image based finite element models. Med Eng Phys 29 : 316-325, 2007

2. Babayev M, Lachmann E, Nagler W : The controversy surrounding sacral insufficiency fractures: to ambulate or not to ambulate? Am J Phys Med Rehabil 79 : 404-409, 2000

3. Barber SM, Livingston AD, Cech DA : Sacral radiculopathy due to cement leakage from percutaneous sacroplasty, successfully treated with surgical decompression. J Neurosurg Spine 18 : 524-528, 2013

4. Basile A, Tsetis D, Cavalli M, Fiumara P, Di Raimondo F, Coppolino F, et al. : Sacroplasty for local or massive localization of multiple myeloma. Cardiovasc Intervent Radiol 33 : 1270-1277, 2010

5. Bastian JD, Keel MJ, Heini PF, Seidel U, Benneker LM : Complications related to cement leakage in sacroplasty. Acta Orthop Belg 78 : 100105, 2012

6. Butler CL, Given CA 2nd, Michel SJ, Tibbs PA : Percutaneous sacroplasty for the treatment of sacral insufficiency fractures. AJR Am J Roentgenol 184 : 1956-1959, 2005

7. Cabarrus MC, Ambekar A, Lu Y, Link TM : MRI and CT of insufficiency fractures of the pelvis and the proximal femur. AJR Am J Roentgenol 
$191: 995-1001,2008$

8. Chao LY, Huang YH, Chih WH : Sacral insufficiency fracture diagnosed after vertebroplasty for $\mathrm{L} 2$ and $\mathrm{L} 3$ compression fractures: a case report. Acta Orthop Belg 78 : 139-143, 2012

9. Choi KM, Song JH, Ahn SK, Choi HC : Therapeutic considerations of percutaneous sacroplasty for the sacral insufficiency fracture. J Korean Neurosurg Soc 47 : 58-63, 2010

10. Daubner D, Seifert J, Stroszczynski C : CT-fluoroscopy assisted percutaneous sacroplasty in management of a pathologic fracture in osteoradionecrosis. Rofo $180: 353-355,2008$

11. Deen HG, Nottmeier EW : Balloon kyphoplasty for treatment of sacral insufficiency fractures. Report of three cases. Neurosurg Focus 18 : e7, 2005

12. Denis F, Davis $S$, Comfort $T$ : Sacral fractures: an important problem. Retrospective analysis of 236 cases. Clin Orthop Relat Res 227 : 6781, 1988

13. Dougherty RW, McDonald JS, Cho YW, Wald JT, Thielen KR, Kallmes DF : Percutaneous sacroplasty using CT guidance for pain palliation in sacral insufficiency fractures. J Neurointerv Surg 6 : 57-60, 2014

14. Evans AJ, Jensen ME, Kip KE, DeNardo AJ, Lawler GJ, Negin GA, et al. : Vertebral compression fractures: pain reduction and improvement in functional mobility after percutaneous polymethylmethacrylate vertebroplasty retrospective report of 245 cases. Radiology 226 : 366-372, 2003

15. Frey ME, Depalma MJ, Cifu DX, Bhagia SM, Carne W, Daitch JS : Percutaneous sacroplasty for osteoporotic sacral insufficiency fractures: a prospective, multicenter, observational pilot study. Spine J 8 : 367-373, 2008

16. Fujii M, Abe K, Hayashi K, Kosuda S, Yano F, Watanabe S, et al. : Honda sign and variants in patients suspected of having a sacral insufficiency fracture. Clin Nucl Med 30 : 165-169, 2005

17. Garant $M$ : Sacroplasty: a new treatment for sacral insufficiency fracture. J Vasc Interv Radiol 13 : 1265-1267, 2002

18. Grangier C, Garcia J, Howarth NR, May M, Rossier P : Role of MRI in the diagnosis of insufficiency fractures of the sacrum and acetabular roof.

Skeletal Radiol 26 : 517-524, 1997

19. Gupta AC, Chandra RV, Yoo AJ, Leslie-Mazwi TM, Bell DL, Mehta BP, et al. : Safety and effectiveness of sacroplasty: a large single-center experience. AJNR Am J Neuroradiol 35 : 2202-2206, 2014
20. Gupta R, Mittal P, Mittal A, Mittal K, Gupta S, Kaur R : Additional merit of coronal STIR imaging for MR imaging of lumbar spine. J Craniovertebr Junction Spine $6:$ 12-15, 2015

21. Jayaraman MV, Chang H, Ahn SH : An easily identifiable anatomic landmark for fluoroscopically guided sacroplasty: anatomic description and validation with treatment in 13 patients. AJNR Am J Neuroradiol 30 : 1070-1073, 2009

22. Lee YJ, Bong HJ, Kim JT, Chung DS : Sacral insufficiency fracture, usually overlooked cause of lumbosacral pain. J Korean Neurosurg Soc 44 : 166-169, 2008

23. Lin JT, Lane JM : Sacral stress fractures. J Womens Health (Larchmt) $12: 879-888,2003$

24. Lourie $\mathrm{H}$ : Spontaneous osteoporotic fracture of the sacrum. An unrecognized syndrome of the elderly. JAMA 248: 715-717, 1982

25. Marcy PY, Palussiere J, Descamps B, Magne N, Bondiau PY, Ciais C, et al. : Percutaneous cementoplasty for pelvic bone metastasis. Support Care Cancer 8 : 500-503, 2000

26. Richards AM, Mears SC, Knight TA, Dinah AF, Belkoff SM : Biomechanical analysis of sacroplasty: does volume or location of cement matter? AJNR Am J Neuroradiol 30 : 315-317, 2009

27. Ries $T$ : Detection of osteoporotic sacral fractures with radionuclides. Radiology 146 : 783-785, 1983

28. Slipman CW, Lipetz JS, Jackson HB, Vresilovic EJ : Deep venous thrombosis and pulmonary embolism as a complication of bed rest for low back pain. Arch Phys Med Rehabil 81 : 127-129, 2000

29. Smith DK, Dix JE : Percutaneous sacroplasty: long-axis injection technique. AJR Am J Roentgenol 186 : 1252-1255, 2006

30. Taillandier J, Langue F, Alemanni M, Taillandier-Heriche E : Mortality and functional outcomes of pelvic insufficiency fractures in older patients. Joint Bone Spine 70 : 287-289, 2003

31. Whitlow CT, Yazdani SK, Reedy ML, Kaminsky SE, Berry JL, Morris PP : Investigating sacroplasty: technical considerations and finite element analysis of polymethylmethacrylate infusion into cadaveric sacrum. AJNR Am J Neuroradiol 28 : 1036-1041, 2007

32. Zerwekh JE, Ruml LA, Gottschalk F, Pak CY : The effects of twelve weeks of bed rest on bone histology, biochemical markers of bone turnover, and calcium homeostasis in eleven normal subjects. J Bone Miner Res 13 : 1594-1601, 1998 